\title{
The Construction of Female Images in American Sitcoms A Case Study of Friends
}

\author{
Luo Wei \\ Film \& Television Arts and Culture, Yangtze University, Jingzhou, China \\ Email: 454230810@qq.com
}

\begin{abstract}
In the classical sitcom Friends, female images are constructed to become authentic, vivid and rounded. The portrayal of costume, appearance and other external factors indicates the inherent meaning of each character, allowing for a constant change and development of personality. The female images in the sitcom are both "looking" and "being looked at", which highlights the multiplicity and richness of female personality. While female characters are derived from real life, the dramatic and conflictive traits enable them to go beyond real life. Based on an analysis on the female images in Friends, this article intends to provide inspirations for character construction in domestic films and TV dramas.
\end{abstract}

Keywords: Sitcom, Friends, female image.

\section{Introduction}

Friends is an American sitcom first aired on NBC in September 1994. The show revolves around six friends in their 20s and 30s who live in Manhattan, New York City, and tells a series of stories about the ups and downs in the ten years they spend together. As one of the most popular TV shows of all time in America, the series won for Outstanding Comedy Series award at the 54th Emmy Awards. Today, it is still a hit TV show broadcast around the world. Unlike traditional sitcoms, the show features a role allocation of three male characters and three female characters. Its portrayal of female characters is profound, multidimensional and thought-provoking, which remarkably inspires the development of domestic sitcoms. This article will probe into the reasons for the long-lasting popularity of Friends from the perspective of female image construction, so as to provide reference for character construction in domestic sitcoms.

\section{The External and the Internal: Female Image under Transformation and Development}

In terms of character construction, the main characters in TV shows should possess distinct personalities and images, on top of typical and unforgettable features. In addition, the image should evolve as time goes by, together with the change of environment and the development of storyline. As Simone de Beauvoir put it, "one is not born, but rather becomes, a woman. No biological, psychological, or economic fate determines the figure that the human female presents in society: it is civilization as a whole that produces this creature, intermediate between male and eunuch, which is described as feminine". (De Beauvoir, S, 1998) The character's development is not abrupt or out of no reason, but rather gradually achieved as the storyline unfolds. In this way, the character image will be more authentic, and audiences will be able to sympathize with the characters and understand their development. In Friends, the three female characters all possess distinct personalities, but their images do not remain the same all the time. The screenwriter made a good use of the external change (costume) and the internal change (identity) to enable a more smooth and natural development of characters.

In TV shows, costume serves as the basis upon which the external image of a character is constructed. "It is a key element that directors employ to shape character images and create an artistic atmosphere. It is also a delicate artwork elaborated by designers, which constitutes a unique visual landscape by itself." (Xiangjun, Y. \& Jiajia W, 2011) When Rachael led an independent life for the first time, she was ignorant and simple as a waitress in a café. During this period, she mostly wore simple T-shirts and skirts in azure, 
light green and light pink, which highlight her lively, simple and cute characters. The various aprons paired with her costumes add to her a sense of fashion and demonstrate a good aesthetic taste. Later, Rachael became a senior manager in a fashion company through her own efforts. During this period, her outfits are not girly anymore, but replaced by premium suites in black, white and gray. Meanwhile, her previous simple and ignorant personality also develops to become mature and sexy. Apart from costumes, appearance also has an impact on character's personality. In return, one's inner features are reflected by appearance. For example, Monica was fat as a teenage girl, which made her feel inferior and thirst for other's recognition and praise. Even when she became slim as an adult, she could not get rid of this personality. Her perfectionism and competitiveness both reflected the lack of love and inner security. Only continuous attention and praise from others can make up for the trauma she suffered from due to obesity.

While costume and appearance are the external presentation of personality, identity change is an important symbol for the completeness of image. Family and career are the two crucial topics in women's life. In Friends, the three female characters all accomplished identity transformation in marriage and career. In terms of their attitude towards marriage, Rachael transformed from a bride-to-be who were adequately fed and clothed to an independent woman who left her fiancée behind in the church to pursue freedom. Monica embraced a happy marriage by helping her boyfriend to transform from someone afraid of making promises to a responsible and mature man with her tolerance and love. Phoebe had a miserable life story full of twists and turns, but she remained enthusiastic and optimistic. Cynical as she seemed to be, she still chose to believe in love when faced with the true love in her life, and ended up with a traditional family. Additionally, the three female characters all transformed from teenage girls to mothers. Rachael became a mother by accident, but she made a brave decision to raise the child up. Phoebe selflessly became a surrogate mother for her half-brother, whereas Monica adopted a pair of twins after marriage. In terms of career, the screenwriter did not depict the three female characters as career women. Instead, they all worked with what interested them. Rachael liked reading fashion magazines, so she became an executive in a fashion company. Monica always wanted to be the hostess, so she became a chef in a fancy restaurant. Phoebe was free and easy without too much materialistic demand, so she did not have a fixed job but worked as a singer or a massage therapist. As their identities reflect authentic personalities and multidimensional images, their images were constructed to be more vivid, authentic and convincing.

\section{Looking and Being Looked At: Rounded and Rich Personality}

In "Visual Pleasure and Narrative Cinema", American feminist film theorist Laura Mulvey proposed the idea of "woman as image, man as bearer of the look". She believed that "In a world ordered by sexual imbalance, pleasure in looking has been split between active/male and passive/female. The determining male gaze projects its phantasy on to the female form which is styled accordingly". (Yuanying, Y, 2017) In Friends, females are bearers of the look as well as the objects being looked at. The coexistence of "looking" and "being looked at" highlights the multiplicity and richness of female personality.

As can been seen from classical American TV shows, although there are various types of female images, the construction of female personality always follows a fixed pattern. For a certain type of female character, we can even find its counterparts in different shows. For example, Charlotte in Sex and the City, Bree in Desperate Housewives and Claire in Modern Family all represent the "perfect housewife" who serve their husbands and children while keeping the house in order, even sharing mysophobia and obsessive-compulsive disorder in personality. Gabriel in Desperate Housewives and Gloria in Modern Family are both charming exotic beauties who rely on their husbands for a rich life, have a sharp sense of fashion and a strong passion for shopping. Miranda in Sex and the City, Lynette in Desperate Housewives and Claire in Modern Family all fall into the category of career women who are decisive and generous as leaders both at work and at home. These three types of female personalities are obviously to the aesthetic interest of men, as they can be combined to become the standard of a perfect wife for men: virtuous, beautiful, and smart. In this sense, men possess the right of "looking" whereas women serve the ultimate purpose of "being looked at".

Although the female characters in Friends are still subject to the character design of "being looking at", they are gradually transforming to bearers of the look with a rounded and multidimensional personality. The three female characters are all highly independent and do not reply on male characters such as fathers and boyfriends. For example, Monica desired to build a family to serve husband and children, but she 
could not have a stable relationship after dating many men. Even with Richard who was mature and caring, she still followed her heart to break up when they disagreed on whether to have children or not. At the beginning of the show, Rachel, in her wedding dress, pushed the door of the café open in a panic. At that moment, she gave up the extravagant life her fiancée could provide her as well as her identity as a highborn lady, because she did not want others to manipulate her life. Rachael's unruly younger sister had been dependent on her husband and mother without working to gain financial independence. However, she was also influenced by Rachael to get rid of her reliance on men and fulfilled the value of life by becoming independent.

With an overall view of the show, the personalities of female characters are not homogenous or stereotypical but multidimensional and complicated. Monica longed to return to traditional family but did not lower her standard to please others; Rachael was sensitive and reliant, but bold enough to get out of her comfort zone and fight for her career. The awakening of feminine consciousness and the breaking away from male dominance render female characters' personalities in this show more rounded, multidimensional and distinctive.

\section{Identification and Pleasure: Combine Drama and Reality in Character Design}

Sitcoms feature long time spans. For example, Friends was broadcast for 10 years from the first episode to the last episode. Consequently, audiences became familiar with characters in the show as if they were old friends. Audiences felt what happened to the characters also happened to them, and they grew altogether. Undoubtedly, successful character construction is bound to be based on life but beyond life. Moreover, character design should be full of drama and conflicts, so as to add a hint of sentiment to the overall tone based on life stream narration. In this way, the character will have artistic and aesthetic values which drive audiences to watch the show.

According to Lacan's mirror stage theory, "the subject's fate is always to face 'self as other' and 'other' as self". (Fukuhara, Taihen, 2002) In a good sitcom, characters are designed to be close to reality. Their words and behaviors will influence audiences, making them feel as if they were there as well. While watching the show, audiences no longer stand by but integrate themselves into the storyline. They can see themselves in characters, as if looking into a mirror. According to Metz's identification mechanism, "the second dimension of identification is closer to audiences' self-perception based on experience. It refers to our watching experience in the cinema which mixes reality with fiction as well as our experience with others' experience. In this case, we are able to project self-perception onto ideal characters with special life". (Dai, Jinhua, 2004) In Friends, the design of female characters arouses a strong sense of identification among audiences. For example, Monica's elder brother obtains a PhD degree, so she is always disappointing in her parents' eyes. In childhood, she did not have many friends due to obesity. Even when she became beautiful after losing weight, she still lacked confidence. This is a true portrayal of real life. None of the characters is perfect, as they all share the same weaknesses and trouble with ordinary people. Rachael is materialistic, Monica is a control freak, and Phoebe suffers from neuroticism. The female images in the show are representative and universal, as each of them represents a group of people in real life. Through "oppositional reading" and "negotiated reading" as such, Friends evokes audiences' sense of approval to the best.

However, the construction of female characters goes beyond authentic. In the show, female characters no longer serve as mere eye candies to contrast others. Instead, they play an indispensable role in portraying character's emotion and promoting the development of the storyline. The development of many important plots is motivated by female characters. The design of these plots makes characters beyond real life, enriching the content of the sitcom for a better watching experience.

As John Fiske put it, "The work of popular pleasure takes two main forms: evasion (or offensiveness) and productivity...Their resistance is one of refusal, not of a semiotic insurgence." (Fiske, John, 2010) Generally speaking, most females have an insipid and even dreary love life without passion. From relationship, marriage to childbirth, they follow fixed procedures throughout life. In contrast, the female characters in Friends enjoy a more colorful love life full of desire, which is unavailable for ordinary people. With different love stories, they provide audiences with more room for imagination. For example, Ross and Rachael went through a series of stages including secret admiration, relationship, breakup, reconciliation, 
second breakup, marriage, divorce, childbirth and second reconciliation. Their affairs are throughout all the episodes. In the development of storyline, they both constantly dated and even married others, only to find out that they were made for each other at the end. Besides, the life stories of characters in the show are rather dramatic. For example, Phoebe, one of the main characters, had an unusual and strange life. When she was young, she was abandoned by her mother, and her father ran away from home. What's worse, her step mother committed suicide, and her twin sister treated her as a strange. Before meeting the other five friends, she used to live on the street, fought with policeman and befriended all kinds of weirdos. Compared with the other two female characters, she is more capable of seeing through the nature of life, because she has gone through more hardships in life. The existence of Phoebe reveals the other side of life, bringing audiences a sense of mystery and freshness. Last but not least, Friends creates a social circle where friendship is above everything. Within this circle, friends will always be by your side no matter what happens. Even in the middle of conflicts, several words of explanation and a hug will resolve all the contradictions. United as a whole, the six friends rely on and accompany each other all the time. While watching the show, audiences will start to expect perfect friendship and long for a relaxing social circle. However, such kind of friendship and life style are idealized and dramatized. Based on John Fiske's theory, many audiences watch Friends to escape from reality. They acquire a cultural space for themselves to run away from all the trifles in real life. By identifying with the dramatic stories in the show, they fancy exchanging roles with characters and gradually get lost in sensual pleasure. In a temporary exemption from the control and surveillance from society, such kind of disorientation symbolizes jouissance.

Art derives from life but goes beyond life. Excellent character design serves as a mirror of life, which represents the personality and living conditions of ordinary people truthfully. However, the character construction is not rigidly adhere to real life, but portrays characters based on the development of storyline and personality. In this way, audiences will be touched deep down and resonate with the show. They will feel a strong pleasure when identifying with characters.

\section{Conclusion}

Within ten episodes, Friends tells a story about a group of young people going through ups and downs in relationship, career and emotion. The show touches us deep down with a sense of youthfulness. It does not beautify female characters, avoid deficiencies in personality nor exaggerate contradictions and conflicts. The three main female characters are constructed to be authentic, multidimensional and rounded. Their internal development of personality is depicted through external factors. Breaking through the constraints of females "being looking at", characters now have more multidimensional and rich personalities. Based on life but beyond life, the character design meets audiences' expectation and allows them to identify with characters. As an important category of TV shows, sitcoms are significant for enriching people's spiritual life. The success of Friends provides considerable inspirations for Chinese sitcoms, especially in the depiction of female characters. Compared with American sitcoms, the development of Chinese sitcoms is not ideal. Good works do occur occasionally, but there is a wide gap between Chinese and American sitcoms in terms of quality and quantity. In most Chinese sitcoms, the portrayal of female characters is often stereotypical and homogeneous, some even rendering female characters inferior to male characters. Lacking in innovation, some production teams borrow character image and storyline from American sitcoms blindly without selection. With a big market for sitcoms, Chinese TV show production institutions should learn from others and consider the real situations of domestic audiences to produce classical sitcoms.

\section{References}

1. De Beauvoir, S. (1998), "The Second Sex (Tiezhu T., Trans.)," Beijing. China Book Publishing House, pp.309.

2. Xiangjun, Y. \& Jiajia W. (2011), "The consumerism spread by costumes in film and TV seires," Literature \& Art Studies, no. 4, pp. 146-148.

3. Yuanying, Y. (2017), "Film Theory Textbook," Beijing. United Publishing Company, pp.527.

4. Fukuhara, Taihen. (2002), "Lacan: Mirror Stage," (Xiaofeng, W. \& Zhuofan, Li., Trans.) Shijiazhuang, China. Hebei Education Publishing House, pp.248. 
5. Dai, Jinhua. (2004), "Film Criticism," Beijing. Peking University Press, pp.160.

6. Fiske, John. (2010), "Understanding Popular Culture". New York. Routledge, pp.40-43. 